\title{
Editorial note: Entrepreneurial characteristics and internationalization in the emerging death of distance
}

\author{
Hamid Etemad
}

Published online: 25 March 2014

(C) Springer Science+Business Media New York 2014

The main theme underlying this issue is internationalization and entrepreneurial characteristic, including the entrepreneur's propensity to create personal links, establishing new inter-firm networks, joining existing networks, acquiring resources, from within and outside networks, and devise internationalization strategies using, or leveraging, network advantages and connections. Within this common theme, there are few significant sub-themes in the four articles presented in this issue, adding diversity and richness to the discussions. The issue also presents a rich variation in the firms' home-base, industry, orientations and size as well as the choice of methodologies. This editorial will first highlight the selective aspects of each article, followed by observations on related topics, before offering some comments at the end.

The first article, co-authored by Waleed Omri and Audrey Becuwe, is entitled as "Managerial Characteristics and Entrepreneurial Internationalization: A Study of Tunisian SMEs". Early on, this article observes that the traditional theories of International Business (IB) did not consider top management as a key factor in, and paid relatively little attention to, the possibility of top management playing a critical role in formulating and implementing effective internationalization strategies. This disregard of a vital factor may not have been a crucial omission in the traditional IB theories focused on the large firms with large hierarchical and dispersed management structures. However, a body of research suggests that the founding entrepreneur(s), or small entrepreneurial team, do indeed play influential roles in smaller firms' decisions and consequent growth, including internationalization. Views on the role of manger range from a "rational maximizer" at one extreme, to behaviourally- and contextually-oriented on the other extreme. The former reflects the basic assumption implicit in the economic theory of the firm - where the firm is assumed to be resource-rich and capable of acting rationally; and the management is required to maximize returns, given the state of information and the perceived uncertainty. In the latter, where management decisions are concentrated in small number of entrepreneurs and small top management teams

H. Etemad $(\bowtie)$

McGill University, Montreal, QC, Canada

e-mail: hamid.etemad@mcgill.ca 
(TMTs) of smaller entrepreneurial firms with constrained resource and relatively inexperienced managers, the management is under pressure to adopt innovative strategies and behave entrepreneurially to compensate for their relative shortcomings and meet pressing challenges, including the paucity of information and the higher perceived uncertainty associated with their firm's smaller size, limited network, and comparatively less powerful board of directors. Although these two basic positions are not mutually exclusive, the managers' orientation and their corresponding contemporary behaviour impact the firm's strategic orientation and the consequent outcomes. Manifestation of managers' decisions and corresponding actions are externally observable and objectively measureable, which enable the research to engage in exploring the impact of managerial characteristics on developing competitive advantages, innovative strategies, internationalization, their logical combination thereof, and tracing their impacts on firm's performance and management's observed behaviourial attributes and patterns. Based on that premise, researchers would be able to raise a few fundamental questions: how are managerial orientations formed, what factors influence the process of their formation and evolution over time and across different circumstances, how do they relate to firms' performance and internationalization and how a firm's prevailing circumstances impact managers' behavioural patterns? This brief background discussion would provide a context for the research presented in the articles of this issue.

In the first article of this issue, the managers' innovative behavior is defined in terms of "five main factors: personality traits, Islamic ethics, mental ability, social capital and human capital". These "main factors" are assumed to have direct and indirect impacts on internationalization. Eleven hypotheses address the various relationships. The first five hypotheses (H1 to H5) articulate the direct relationship between the "five main factors" and "internationalization behavior". Another five (H6 to H11, excluding H7) formulate the relationship between the "five main factors" and the manager's emotional intelligence (EI) and creativity, while one hypothesis (H7) highlights the relationship between the manager's personality traits and Islamic Ethics. After adopting all the pertinent scales for measuring all variables of interest in a questionnaire, 412 managers of Tunisian SMEs, representing various sectors of the economy in Tunisia's small open economy, were invited to participate in the study, from which the 289 completed replies were further analyzed. A co-variance-based structural equation modeling (SEM) was used to simultaneously test validities of measurement constructs and structural modeling of the study.

A detailed discussion of statistical analysis points to many interesting findings: i) that there are structural paths from the five "main factors" to Internationalization, ii) three of these "main factors" (Personality traits, mental ability and social capital) obtained a positive and significant coefficients, while, iii) the remaining two of the "main factors" failed to obtain statistical significance. Regarding the full model, a robust model is estimated to provide both a comprehensive picture of the relationship between the "five main factors" and the internationalization behaviour, including the direct, indirect and mediating effects. This model provides collective support for the second set of hypotheses (H6 to H11).

The findings point to significant direct effects of "personality traits" and also to the moderating effect through "mental ability" on internationalization behavior. More significantly, "social capital", has a direct effect on "international behavior" while transmitting the moderating effect of "human capital" directly and indirectly through 
"mental ability"; thus effecting the "international behaviour". In short, managers' characteristics have direct and indirect impacts on their firms' internationalization and behavioural outcomes. Neither are the participating manages formulaic maximizers or optimizers; nor would their firms follow a rigid pre-determined path of internationalization.

The second paper in this issue, co-authored by Tobias Kollmann and Julia Christofor, is entitled as "International Entrepreneurship in the Network Economy: Propensity and the Role of Entrepreneurs Orientation". As the title indicates, different factors influencing the internationalization of firms are examined. While the German networked economy context is very different from the open small economy of Tunisia, the aims of the studies are similar-exploring "the role of entrepreneur making the internationalization decisions in the context of nascent ICT-based start-up". This study also adopts a holistic perspective that includes the influential characteristics of the firm's founder and business model in influencing the internationalization path of ICTbased entrepreneurial firms, which in turn are effected by the entrepreneur's entrepreneurial orientation (EO).

Two particular aspects of this research are of interest and set it apart from the others:

First, the Germans ICT-based firms operate mainly in an Internet-based environment, which allows these firms to capitalize on their interactivity with their customers very effectively in terms of acquiring more information about their customers' profiles, preferences and behaviours at low transaction costs. In contrast to the traditional production factors, capital and labour play less significant roles in ICT-based firms' model, as the critical input factors in their production function are information, knowledge (e.g., intellectual capital and intellectual property) and their products are also ITC-based. They also enjoy a relatively low production costs with very little, and possibly no, replication and transmission costs.

Second, ICT-based firms are different from traditional firms in their use of electronic value net, giving them virtual access to buyers, suppliers, competitors and complimentors (at low to no costs), regardless of their time and location. Therefore, their location and distance to markets play insignificant roles in their operation, to which they refer as the "death of distance".

Similar to the first paper, the second paper suggests that the founders and their associated entrepreneurial orientation (EO), embedded both in their firm's structure and corporate culture as well as in their environmental context, collectively determine the firm's market orientation (MO), which may range from domestic market to international market orientation. Naturally, there will be some interactions amongst the EO, $\mathrm{MO}$, the firm's resources, competitive advantages and strategies. After a long and thorough examination of the literature and proper allowance for the ITC context of the study, the paper proposes six hypotheses, each articulating the influence of one of the six specific characteristic of the industry on the firms', and the industry's (by logical extension), internationalization. The six proposed hypotheses suggest relationships between internationalization and: the high degree of digitization of products and processes, the high degree of scalability of products and processes, the need for high degree of protecting the properly rights, the low degree of resource commitments, the 
high degree of highly internationalized network and high international market orientation. Using a conjoint analysis, these hypotheses are tested on a random sample of 1,120 firms, drawn from a carefully constructed population of "Internet firms". A confirmatory cluster analysis identifies four distinct groupings enabling a comprehensive discussion of the influential factor(s) in the presence of other characteristics that have different intensities in different clusters in the industry. Expectedly, the findings of this paper lend further support to the first paper's findings in spite of the ICT industry's specific context.

As compared to the discussion of connections, linkages and networks at the broad industry level highlighted in the second article, which constitutes the distinguishing context of the ICT firms in Germany, the third article in this issue focuses on micro and operational level of connections. It addresses the actual process and dynamics of establishing a cross-border inter-firm linkage between two relatively smaller firms in different geographical markets. The article co-authored by Giulio Buciuni and Lapo Mola, is entitled as "How do Entrepreneurial Firms Establish Cross-border Relationships? A Global Value Chain Perspective". The authors review the literature of smaller firms to document the shortcomings of these firms in highly competitive industries, where there is no allowance for lack of high (e.g., global) competitiveness, due to adversities of firm's smaller size or the state of its poor resources, among others. The specific context within which the research of this paper is situated is Auto industry, which is a highly competitive and globalized industry, especially for industrial products in the European and North American markets. The primary question for small and resource poor firms with specialized products, usually facing a limited demand in a market niche, is how to respond to demand, grow in, and internationalize from, such markets? Although this is not the research question of this article, it is a primary, if not an existential question that pre-occupies smaller firms early in their operations. Among the various theories of growth and internationalization, the network theory offers viable and simple theoretical option. However, operational counterparts are far from clear or simple. This article chronicles the actual efforts involved in establishing an inter-firm and cross-border alliance between two firms in the same specialized sector of the global industry, where many critical operational and strategic problems need to be solved at the same time if an alliance can form, survive and grow over time. The list of fuzzy internal problems in need of early clarification by most smaller firms include the absence of a logical clarity in governance structure, a reasonable precision in the magnitude of actual costs and the value-added of the firm's micro activities. This need for clarity poses a problem when partners need to contribute (and share) some of these value-adding activities to the partnership to form the joint value chain of their alliance. Such lack of clarity and precision is a fertile ground for brewing conflict and disagreement that can threaten joint operations, if not demise, of the partnership. In typical small firms, most activities and their consequent outcomes are not usually standard, not benchmarked widely, nor are they commodities with established international prices to avoid attribution problems arising from lack of clarity and precision. As a result, when it comes to evaluation of each partner's contributions to the alliance as a basis for distribution of corresponding rewards, partners suffer from the absence of clear, fair or objective costs and values, causing the prospect of difficult attribution and distribution disputes. Therefore, designers and managers of proposed alliances need to devise solutions before making commitment to joint operations to avoid crippling problems 
afterwards, when massive human efforts and resources, involving high opportunity costs, are already spent on negotiating alliances.

Due to the privileged position of one of the authors, the authors selected an in-depth case study method to document many "why" and "how" questions involved in the formation, operation and management stages of the joint alliance. As a result, the paper discusses in some detail the situation of each firm, one located in Bologna (Italy) with revenues of \$22 million in 2010 and 30 employees; and the other in North Carolina (USA) with revenues of $\$ 8$ million in 2010 and 28 employees; each firm building specialized industrial trucks. The authors also adopt, and discuss, the global value chain (GVC) as an analytical framework for examining such problems. They report that GVC is capable of envisioning some of the emerging difficulties and even sheding lights on some of those problems facing the alliance managers in their joint operations.

The fourth article of this issue, co-authored by Vishal K. Gupta, Golshan Javadian and Nazanin Jalili, is entitled as the "Role of Gender and Management Style in Influencing Perceptions and Behaviors of New Recruits: Evidence From the Islamic Republic of Iran". As in the case of the third paper, entrepreneurs and small entrepreneurial firms suffer from constrained resources, which remain as the main crippling challenge before the firm crosses-over the size threshold. An important resource to any smaller firm is its human resources. Naturally, the quality of the human resources, in terms of their efficient performance by functioning well within the firm's leadership style and effective team-membership within a given corporate structure, have vital importance to all firms, especially to those suffering from poor and constrained resources. It is not an exaggeration to state that the high quality of the early recruits significantly impacts the growth path of any firm from the start, especially when startups need to heavily rely on the contribution of their early employees' intellectual capital and efforts.

On the other side of the same coin, efficient employees, having high quality human capital demanded by other competing firms, would also be looking for highly effective leadership, highly conducive organizational structure and policies to capitalize on their human capital, to be fairly recognized (and rewarded) for their accomplishments and efforts to grow and advance within the firm. Therefore, not only entrepreneurs need to assess the recruits for best possible employees, potential employees need to evaluate the firm for its potential success enabling their growth within the firm and their eventual mutual long-term success. In short, there is an on-going, deep, and intense, evaluation process of prospects, both in the short and long terms and on both sides of the coin-on the side of the potential employees and the employers. Such evaluations are fraught with the asymmetry and paucity, if not the lack, of objective information on either side: neither can each side access complete and objective information, nor can they evaluate them effectively and objectively. As a result of limited, selective, and even subjective, information, less-than-complete evaluations will form the basis for decisions. The above discussions portrays the difficulties and the uncertainties experienced by entrepreneurial firms trying to recruit the best potential employees (and acquire resources in general), while high quality potential recruits also face the same difficulties in evaluating the firm during their limited recruitment interactions. This paper comes close to characterizing such imperfect interactions by simulating the interaction between the two parties - entrepreneurs (and entrepreneurial firms) searching for the best employees as potential recruits and potential employees implicitly and quietly evaluating 
the quality of the firm's leadership characteristics - through two well-designed experimental studies with university students in a behavior laboratory context. Three hypotheses were designed to assess the impact of the interaction between the entrepreneur's gender and management style with the recruits as well as measuring the recruits' affective reaction to working for the entrepreneur (in the first experiment), and then assessing the recruits' evaluation of the entrepreneurs' effectiveness and their own performance in team task environments (in the second experiment) in view of that leadership. The findings were not symmetrical: while management styles (directive and participative) and the gender of the women entrepreneurs interacted in recruits' evaluations, it did not appear to matter for male entrepreneurs. Similar to findings in other papers in this issue, the specific context of the study seem to have had a significant impact.

Back to the "Death of Distance" (proposed and discussed by the second paper). The concept of distance within the ICT-based firms and industry, contrasts starkly with that outside ITC firms in terms of: i) geographic distance is usually giving rise to shipping and other distance-related costs and delays; ii) the psychic distance representing the managerial perception of difference in operating regimes of the home and host country environments is resulting in the expectation of higher operating risks and also higher liabilities of "foreignness", "outsidership", and even "newness"; iii) the firm-client distance (e.g., the distance between the buyers' needs and wants and the firm's product offerings) is playing prominent roles in the success or failure of new products even in the firm's own familiar home market; iv) numerous studies have found that the same concept of firm-client distance in international markets calls for establishing an optimum balance between adaptation versus standardization of product offerings in different international markets; and v) the legal, normative and even cultural distance in crosscultural settings has given rise to the concept of institutional distance posing operational difficulties. Practically all of these distances are positive, evolving significantly and posing challenges, especially when different cross-cultural settings are involved. The inherent difficulty underlying the concept is that most parties of one side have only a subjective (not objective) view of the other side's that cannot be easily bridged-over, or reconciled, as such parties' evaluation is mostly experientially- and contextually-based.

More importantly, however, the above distances have significantly influenced the internationalization decisions and processes as well as occupying the scholarly literature for a long time. If the "death of distance" does, indeed, play a more significant role in ITC-based firms and ITC industry, then the operations of ITC firms need to be viewed differently from those of other firms and industries, including internationalization, mainly due to the context within which they are embedded and operating. Conversely, if the counterparts of the distances discussed above are also on their deathbeds in ITC-based firms and industries, then there is an urgent need in other industries to learn from and emulate the ITC-firms' practices. Such learning and emulation is bound to significantly contribute to the logical clarity of international operations.

Similarity and by a logical extension, the above studies suggest that the impacts of significant environmental differences on the internationalization patterns of these firms need to be explicitly taken into account and seriously evaluated, which calls for multicontext research in entrepreneurial internationalization. Consider for example, the wide gap existing between institutional norms among the advanced and emerging economies 
that is challenging the implicit assumption of applicability of internationalization theories, process and patterns (mostly based on the advanced economies)for firms based, or operating, in the emerging economies. Therefore, the question of how the internationalization patterns and behaviors of firms based in the emerging economies differ from those in the advanced economies, mainly due to the difference in their operating contexts, merits scholarly investigation.

Regarding interactivity and distance, if high interactivity (discussed in the second paper in this issue) has indeed reduced, if not removed, the "distance" between buyers and suppliers in ITC-based products and firms, it stand to reason that the entrepreneurial (and innovation) orientations - EO (as discussed in some length in the first and second papers) have had a significant influence in the direction of firm's market orientation (MO) at home and in international markets. Furthermore, a combination of the low production and transmission costs in the ITC-based products, may have enabled ITC firms to easily respond to different dynamics associated with the "market pull" and "market push" forces giving rise to different internationalization patterns as compared to those in other industries. Therefore, in spite of the theoretical similarity of concepts and constructs, their context may impact their interrelation to give rise to added complexity and richer details requiring deeper understanding of the system as a whole.

In closing, the above discussion suggests that more nuanced concepts and constructs along with more powerful methodologies need to be deployed, to add richness, discover asymmetries and advance the state of theory and practice in International Entrepreneurship. The journal welcomes articles addressing the above and similar family of research questions and problems. 